\title{
Dinâmica molecular: como mostrar um filme completo em uma folha de papel?
}

by Diego Mariano

2 de julho de 2021

Dinâmica molecular: como mostrar um filme completo em uma folha de papel?

Diego Mariano $(\mathbb{D}$, Bruno M. Silva (1D)

Revisão: Leonardo Lima (1)

BIOINFO - Revista Brasileira de Bioinformática. Edição \#01. Julho, 2021.

DOI: 10.51780/978-6-599-275326-11

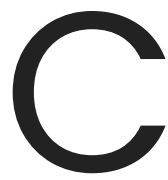

ompreender como as moléculas se comportam pode ser essencial para desvendar seus mecanismos de atuação, o que pode ter diversas utilidades no campo da biologia, como por exemplo, descoberta de novos medicamentos e outros

produtos biotecnológicos. Quando falamos sobre comportamento e mecanismo de ação de uma molécula, estamos nos referindo a sua mobilidade espacial, a como ela se comporta em variações de temperatura (termoestabilidade) e a como ela reage ao interagir com outras moléculas. Em bioinformática estrutural, a técnica responsável por simular computacionalmente o comportamento de moléculas por um período de tempo é denominada dinâmica molecular [1].

Como pode perceber, essa simulação não é um processo simples. Moléculas mais complexas, como as proteínas que formam os nossos corpos, podem possuir dezenas de milhares de átomos realizando diversos tipos de interações entre si. Lembre-se que proteínas são formadas por fortes interações covalentes em suas cadeias principais, além de interações, em geral, fracas entre suas cadeias laterais. Essas interações irão determinar a forma de uma proteína e, consequentemente, seu papel neste mundo cruel. E não podemos nos esquecer que os átomos dessa proteína em questão realizam interações com outros átomos presentes no ambiente (na maioria das vezes, água e sais minerais). Portanto, essa simulação tem um alto custo computacional quando comparado a outros métodos de bioinformática estrutural, como a modelagem de estruturas tridimensionais e o docking molecular (Figura 1). 


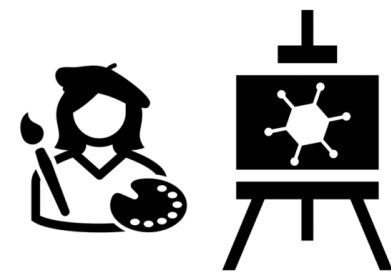

Modelagem de estruturas
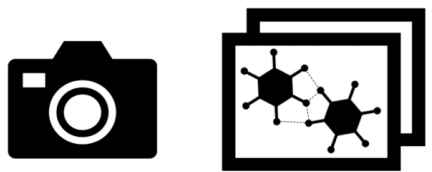

Docking molecular

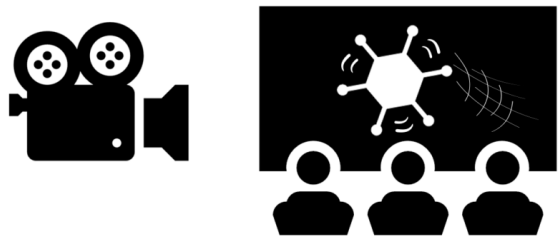

Dinâmica molecular

Figura 1. Se fizéssemos uma analogia, a modelagem de estruturas poderia ser vista como uma pintura, o docking molecular seria como uma foto e a dinâmica molecular seria um filme. Fonte: próprio autor.

A modelagem molecular de estruturas 3D de proteínas refere-se às técnicas computacionais que visam obter a estrutura tridimensional de uma proteína com base apenas em sua sequência (obter sequências por experimentos de bancada é bem mais barato do que obter estruturas). Se pudéssemos representar as metodologias da bioinformática estrutural como coisas do dia a dia, a modelagem de proteínas poderia ser vista como a pintura de um quadro ou um desenho artístico. Vamos supor que você deseja pintar um quadro de sua tataravó na juventude. Entretanto, você não possui nenhum registro visual dela. Nesse caso, teríamos duas formas de produzir essa arte: (i) um desenho comparativo (realizado com base na foto de uma prima que sua avó garante ser a cara da sua tataravó na juventude), ou (ii) um desenho totalmente sem referência (baseado apenas em relatos ou na sua imaginação de como ela seria). No caso da modelagem de proteínas chamamos essas duas possibilidades de modelagem comparativa, quando se possui uma estrutura parecida para servir de referência, e modelagem $a b$ initio (ou modelagem de novo), quando a modelagem é feita com base na sequência usada como entrada e/ou nos dados de restrição espaciais ou campos de força. Não precisamos nem destacar que, assim como a pintura de um retrato realizada apenas com base em sua imaginação, a modelagem $a b$ initio é bem mais complexa que a modelagem comparativa.

Outra analogia que poderia ser feita refere-se ao docking molecular, também conhecido como ancoramento molecular, atracamento molecular, docagem ou apenas docking. Essa técnica visa obter as posições conformacionais de uma molécula quando interage com outra molécula. Um exemplo seria a simulação das interações realizadas por uma proteína com um ligante (pequena molécula). o docking pode ser visualizado como uma foto tirada no exato momento em que as moléculas estão interagindo. Assim como as dezenas de fotos que você tirou no churrasco de aniversário da sua avó (a mesma que pediu para que você pintasse o quadro da sua tataravó), o 
docking requer múltiplas tentativas e análises. Digamos que você teve que tirar fotos até que todos ficassem bonitos na fotografia (ou pelo menos o mais próximo disso). No caso do docking, pode-se utilizar a posição que mais se repete ou a posição que melhor atenda ao protocolo de pontuação utilizado (isso depende da ferramenta usada). Um ponto que devemos destacar é que, apesar dos diferentes métodos de docagem, o resultado final ainda será uma imagem estática. E, assim como uma foto não consegue guardar para a eternidade os detalhes da dancinha malemolente que seu tio fez na festa de aniversário da sua avó, o docking não consegue representar o aspecto dinâmico das interações de uma proteína. Para analisar o comportamento vergonhoso do seu tio precisamos de uma câmera filmadora de alta resolução. Se tratando do comportamento de macromoléculas não podemos filmar (ainda não temos tecnologia suficiente para visualizar em tempo real coisas tão pequenas ou interações que ocorrem absurdamente mais rápido do que um piscar de olhos). A solução é utilizar computadores para simular o que irá acontecer.

Por exemplo, digamos que desejamos simular como um fármaco, que potencialmente poderia ser utilizado para curar uma doença, interage com uma proteína-alvo em determinada parte do corpo humano. Na nossa simulação desejamos ver se o fármaco irá se ligar fortemente à proteína, restringindo seus movimentos. Por isso não podemos apenas observar "uma foto" dessa interação, e sim visualizar essa simulação por um período de tempo, ou seja, como se fosse um filme. Em condições normais, proteína e fármaco estarão envolvidos em ambiente aquoso (vamos desprezar, por enquanto, todas as outras muitas coisas que podem estar lá). Logo, para simular as interações precisamos colocar tanto o fármaco quanto a proteína em uma caixa e enchê-la, por exemplo, de moléculas de água. Os campos de força ilustram numericamente e fisicamente o que irá acontecer quando um átomo ou um grupo de átomos se aproxima de outros. Podemos ter interações de atração ou repulsão. E como todos esses átomos estão dentro da mesma caixa, as interações de determinados átomos impactam nas interações de outros e de outros, gerando um efeito em cascata. Imagine que o átomo $\mathrm{A}$ repulsa o átomo $\mathrm{B}$ posicionado a uma distância $\mathrm{X}$, em um ângulo $Y$, com uma força $Z$. Esse átomo $B$ então interage com um átomo $C$, que interage com um átomo $D$, e assim sucessivamente. Mesmo sistemas simples que armazenam uma proteína, um ligante e uma caixa d'água podem ter dezenas de milhares de átomos. Imagine a quantidade de cálculos que seria necessário realizar a cada janela de tempo. Por isso, esses cálculos de interações átomo-a-átomo não são realizados repetidamente, mas sim a partir de funções e representações. As simulações de dinâmica molecular, em geral, usam campos de força para representar as forças que atuam em um ambiente simulado. Campos de força são parametrizações das interações que podem ocorrer, ou seja, são funções com estimativas de energia. $O$ uso deles permite reduzir a complexidade dos cálculos que deverão ser realizados. Mesmo assim, os custos computacionais ainda são altíssimos.

Falando de uma maneira bastante leiga, podemos dizer que um filme é composto por uma série de fotos tiradas e exibidas em sequência (ignore o 
áudio). Nesse contexto, chamamos cada imagem exibida em um filme de frame (ou quadro). Para detectar movimento, o cérebro humano precisa de aproximadamente 12 frames exibidos sequencialmente por segundo (12 FPS frames por segundo). Abaixo desse valor, o cérebro imagina que se trata apenas de imagens sendo trocadas rapidamente. Na prática, um vídeo abaixo dessa taxa de frames por segundo nos dá a sensação de tremulação, como se o vídeo estivesse "engasgando". Filmes de estúdio, em geral, usam a taxa de 24 FPS. Entretanto, algumas câmeras utilizam sistemas de gravação iguais ou superiores a 60 FPS, o que deixa a imagem mais nítida e reduz os borrões (às vezes, essa nitidez gera uma sensação estranha, por isso taxas de quadro por segundo muito altas não são tão usadas). Em jogos digitais, taxas de FPS altas dão uma sensação de maior qualidade e responsividade. Em simulações de dinâmica molecular utiliza-se conceitos similares para representar cada frame. Entretanto, as interações moleculares ocorrem extremamente rápido. Por exemplo, os movimentos de uma proteína podem ocorrer em uma escala de tempo de até $10^{-15}$ segundos [1], ou seja, em um segundo a proteína já poderia ter repetido esse movimento um quatrilhão de vezes. Por isso, não faz sentido usar escalas tão grandes (como frames por segundo) para simulação de interações moleculares.

Assim, em uma dinâmica molecular costuma-se utilizar a escala de femtossegundo ( $\mathrm{fs}$ ). Um femtossegundos é equivalente a $10^{-15}$ segundos. Por exemplo, em uma simulação de dinâmica molecular, cada frame representa 2 fs. Logo, seriam necessários pelo menos 500 frames para a simulação de 1 ns (equivalente a $10^{-9}$ segundos). Um nanosegundo é o valor de tempo mínimo para observar um movimento de corpo rígido. Para um movimento de grande escala, seria necessário pelo menos $100 \mathrm{~ns}$ (equivalente a $10^{-7}$ segundos; ver quadro abaixo).

Os movimentos de uma proteína podem ocorrer em uma escala de tempo que varia entre $10^{-15}$ e $10^{4}$ segundos. Em geral, esses movimentos podem variar em uma amplitude de 0,01 e $100 \AA$ (leve em consideração que a distância entre carbonos-alfa de dois resíduos de aminoácido vizinhos em uma proteína é de aproximadamente 3,5 A) [1, 2]. Segundo Tousignant \& Pelletier (2004) [1], proteínas podem realizar três tipos de movimentos que influenciam na organização da proteína:

1. Movimentos locais (smallest ou local motions), como flutuações de átomos, movimentos de cadeias laterais ou de loops (ocorrem entre $10^{-15}$ e $10^{-1}$ segundo);

2. Movimentos de corpo rígido (rigid-body motions), como quando uma parte da proteína (como hélices-alfa, subunidades ou domínios) se move em relação a outra (ocorrem entre $10^{-9}$ e 1 segundo);

3. Movimentos de grande escala (large-scale motions), como movimentos de abertura, além de transições de enovelamento e desenovelamento (ocorrem entre $10^{-7}$ e 1.000 segundos). 


\section{Como imprimir um filme?}

Há um grande problema quando se trata de analisar os resultados de uma dinâmica molecular. A forma de divulgação mais utilizada no meio acadêmico é o artigo científico publicado em uma revista periódica. Esse tipo de artigo utiliza textos, figuras e tabelas para resumir, em poucas páginas, os principais resultados da pesquisa. Então, como representar o resultado de uma dinâmica molecular em um artigo? Ou seja, como exibir um vídeo em uma folha de papel?

Você não pode imprimir frame a frame do seu vídeo, mas há algumas estratégias que podem ser adotadas. Como por exemplo, exibir frames mais representativos, mostrar gráficos de RMSD, RMSF, energia de interação, raio de giro, contatos, dentre outros. Nas próximas seções, vamos discutir algumas dessas formas.

\section{Exibindo frames mais representativos}

Você pode escolher as partes mais importantes de sua dinâmica e exibir frames estáticos delas (há programas e técnicas de agrupamento que permitem realizar essa tarefa automaticamente). A vantagem dessa estratégia é que permite que você apresente uma representação visual da sua simulação. A desvantagem é que apenas uma fração mínima da dinâmica será exibida, o que poderá influenciar na percepção do leitor sobre seus resultados. A figura 2 apresenta cinco frames de uma dinâmica molecular.

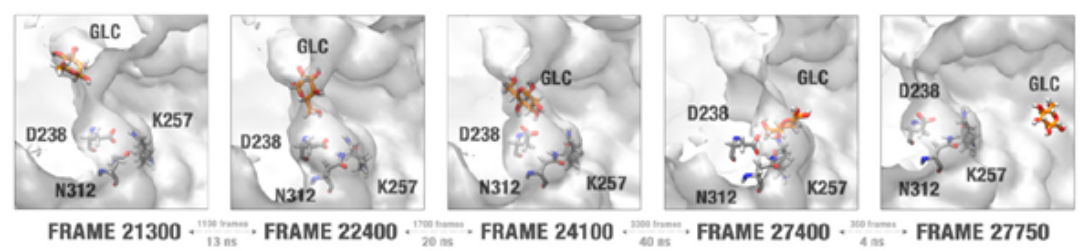

Figura 2. Ilustração de cinco frames de uma simulação de dinâmica molecular. A figura mostra a saída da glicose do sítio ativo de uma enzima beta-glicosidase. Fonte: adaptado de $[3]$.

Pode-se ainda sobrepor os frames mais representativos em uma única imagem (Figura 3). Entretanto, deve-se tomar cuidado com esse tipo de visualização, pois sobrepor muitos frames pode prejudicar o entendimento. 


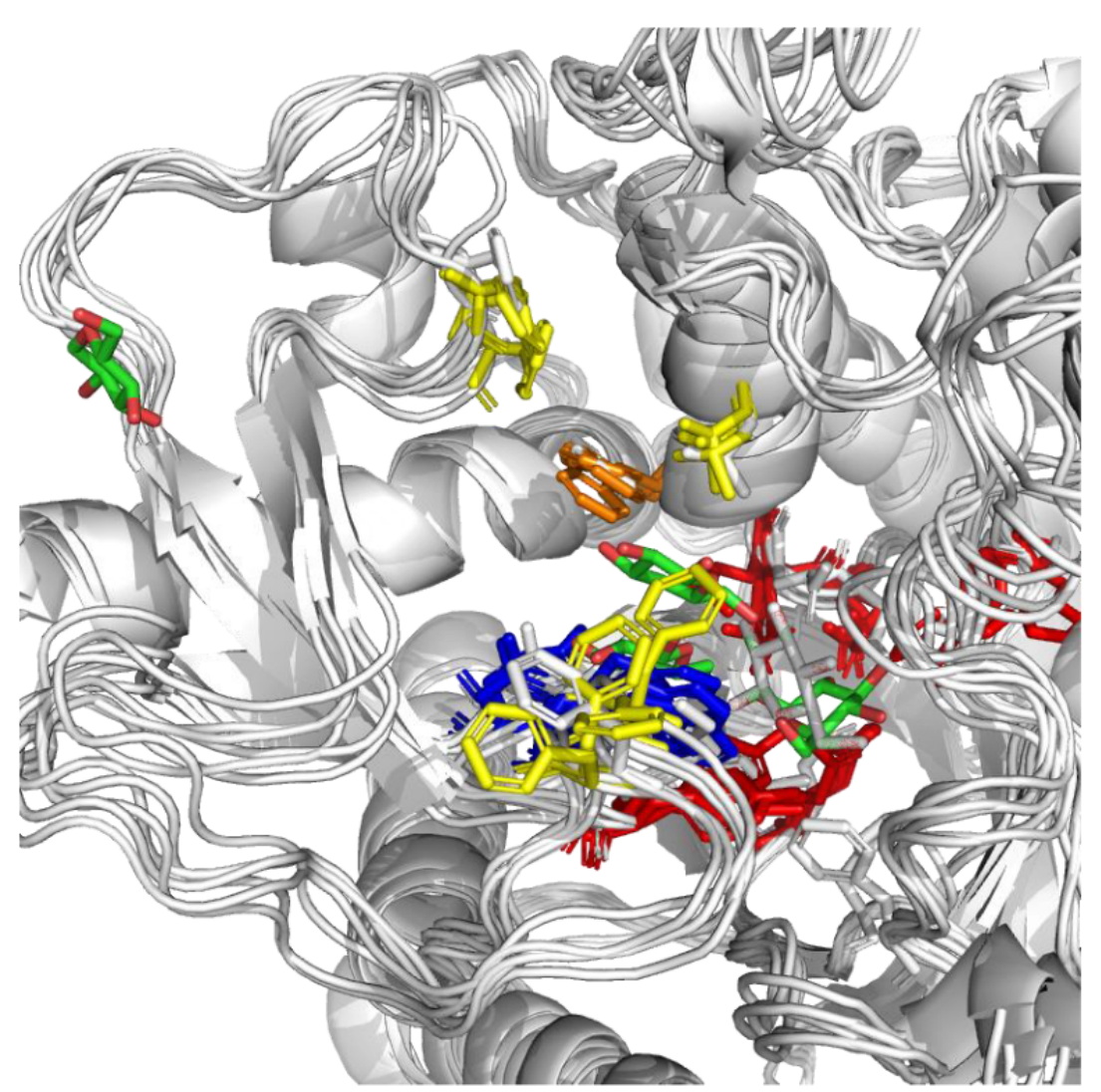

Figura 3. Frames mais representativos de uma dinâmica de beta-glicosidase foram sobrepostos. A estrutura do backbone é apresentada como cartoons cinzas. Alguns resíduos de aminoácidos foram destacados nas cores azul, vermelho e amarelo. O ligante é apresentado em verde. Note que essa figura ilustra como ele se distancia da proteína. Essa visualização é prejudicada pela sobreposição de muitas estruturas. Fonte: adaptado de [3].

\section{Gráfico de RMSD}

Ao avaliar um sistema que está em movimento, você precisa de um gráfico que represente sua mobilidade. Uma forma de fazer isso é utilizar o desvio quadrático-médio das distâncias dos átomos (ou do inglês root-meansquare deviation ou somente RMSD). Nesse tipo de gráfico é feita uma comparação frame a frame da variação das distâncias. Quando o gráfico alcança o platô, ou seja, não tiver mais tantas variações, pode-se dizer que o sistema entrou em equilíbrio, indicando que a proteína, por exemplo, não apresenta mais tantas modificações estruturais. A figura 4 ilustra esse tipo de gráfico. Nela, as linhas indicam o quanto uma molécula se moveu de sua posição inicial. Observe que, após alguns nanosegundos, as linhas se mantêm constantes em aproximadamente 1 Å. Isso indica que o sistema está em equilíbrio. 


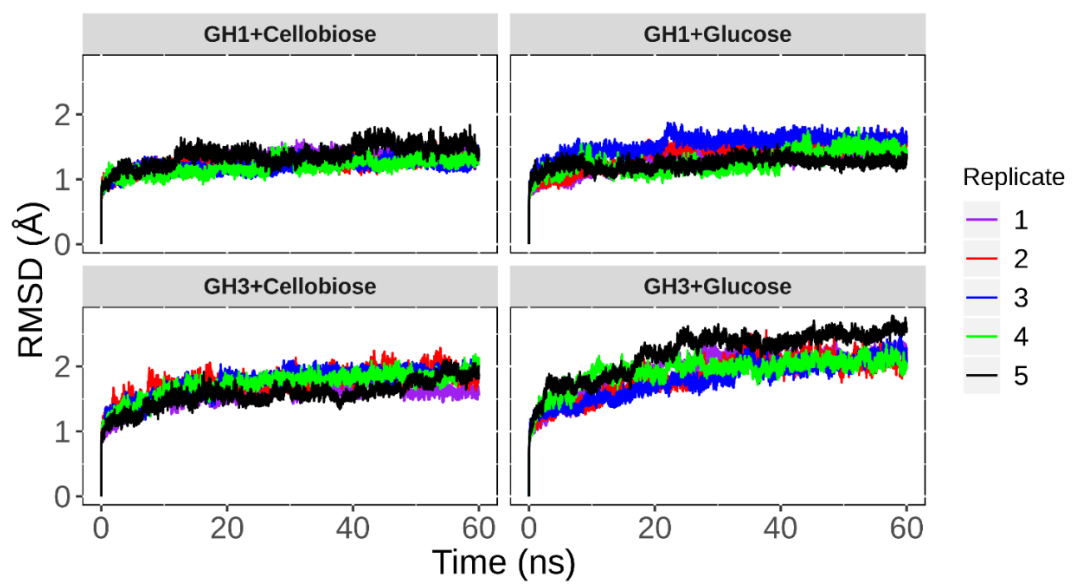

Figura 4. Gráfico de RMSD por tempo para quatro sistemas compostos por enzimas betaglicosidase das famílias $\mathrm{GH} 1$ e GH3 em complexo com glicose e celobiose. O eixo Y indica a variação de distância e o eixo $X$ o tempo. As cores indicam replicatas diferentes. Fonte: adaptado de [3].

Outro exemplo desse tipo é o gráfico de RMSD 2D (Figura 4). Nesse exemplo, vemos um gráfico da mobilidade de uma região composta por quatro loops de nove proteínas homologas e mutantes de beta-glicosidases. Note como as cores quentes indicam claramente quais as mutantes têm maior mobilidade. No gráfico RMSD simples, vemos que cada parte da simulação é analisada em relação ao quão distante ela está de uma única pose de referência (na Figura 4, a pose de referência é a conformação inicial da proteína). Por outro lado, o gráfico de RMSD 2D apresenta uma comparação todos-contra-todos de poses da dinâmica molecular. Nesse caso, as cores variam de azul a vermelho para indicar o quanto a pose em cada quadro no eixo $X$ está próxima do quadro no eixo Y. Perceba que o valor da diagonal sempre será zero, uma vez que ela indica a distância de um frame contra ele mesmo. Ambos os gráficos de RMSD, simples ou 2D, podem ser feitos para uma dinâmica (Figura 4) ou comparando dinâmicas de sistemas parecidos (Figura 5). 


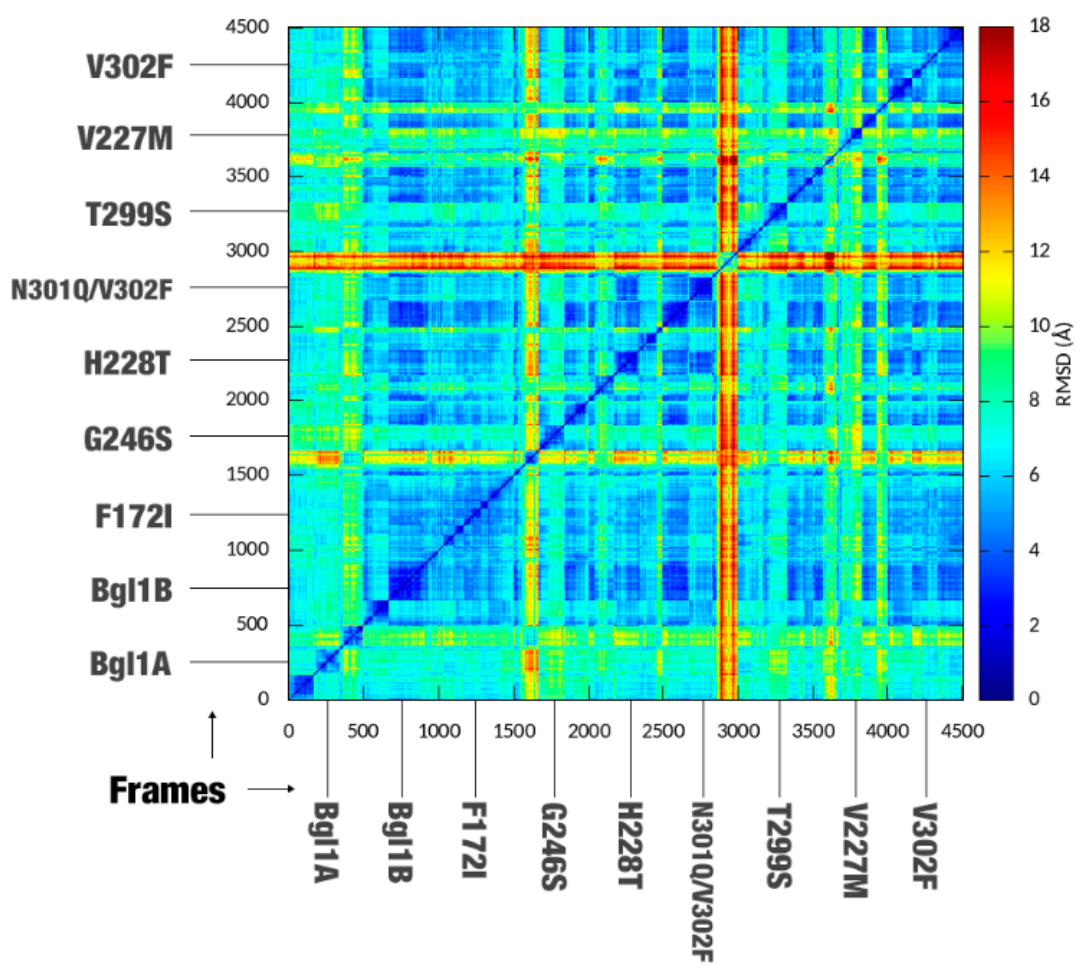

Figura 5 Gráfico de RMSD 2D de uma dinâmica da região de loops (denominada como LA$D-E$ ) de nove proteínas homólogas da família beta-glicosidase (denominadas como Bgl1A, Bgl1B e mais sete mutantes destas proteínas). Note como as cores nos apontam uma clara alta mobilidade nas mutantes N301Q/V302F e G246S (linhas mais avermelhadas). Fonte: adaptado de [4].

\section{Gráfico de RMSF}

O RMSF (root-mean-square fluctuation) corresponde ao RMSD da média ao longo do tempo. O RMSF é um modo de visualizar quais resíduos estão com maior mobilidade espacial. Por exemplo, você pode estar estudando uma mutação em uma determinada proteína. Após a dinâmica, você observa que esse resíduo está bem menos móvel quando comparado com a proteína selvagem. Isso pode implicar em ganhos ou perdas de interações da proteína com o ambiente. A figura 6 ilustra como um gráfico de RMSF por resíduos pode ser utilizado para destacar regiões mais móveis de uma proteína. Observe que os resíduos que apresentam os maiores "picos" estão em regiões de loops. 


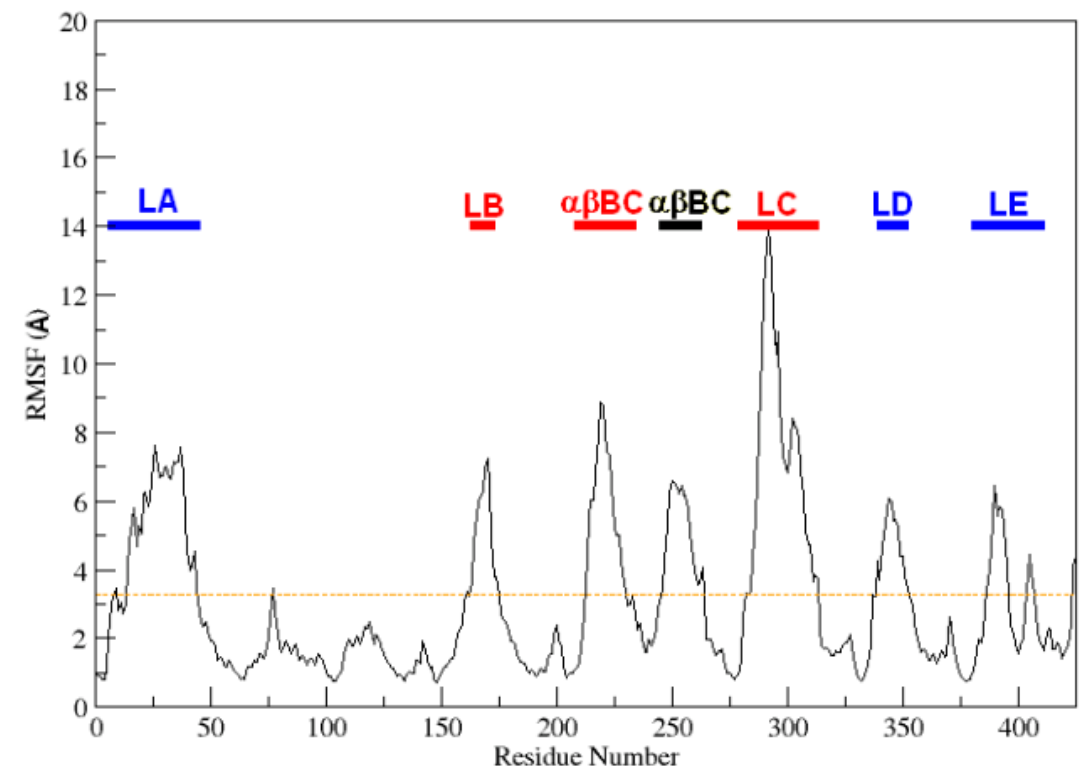

Figura 6. Gráfico de RMSF para os mais de 400 resíduos de uma proteína betaglicosidase. As linhas indicam a variação da mobilidade. Quanto mais alta a linha, maior a mobilidade. Regiões específicas de loops foram grifados acima (como LA, LB, dentre outros). Fonte: adaptado de [4].

\section{Gráfico de energia de interação, ângulo e distância}

O gráfico de energia de interação nos mostra se o sistema adquiriu o seu mínimo enérgico e, com isso, o equilíbrio. Já ângulo e distância podem ser usados para avaliar a mobilidade de ligantes em uma proteína. Esse gráfico também é usado para prever conformações mais adequadas de peptídeos ou proteínas, uma vez que esses sistemas tendem a adquirir uma conformação estável em um vale de energia negativa. A figura 7 ilustra um gráfico que usa cor para representar a energia (dada em $\mathrm{kJ} / \mathrm{mol}$ ), o eixo $\mathrm{X}$ para indicar a distância (dada em ângström) e o eixo Y para indicar a variação de ângulo (veja que o eixo vai de 20 a 120\%).

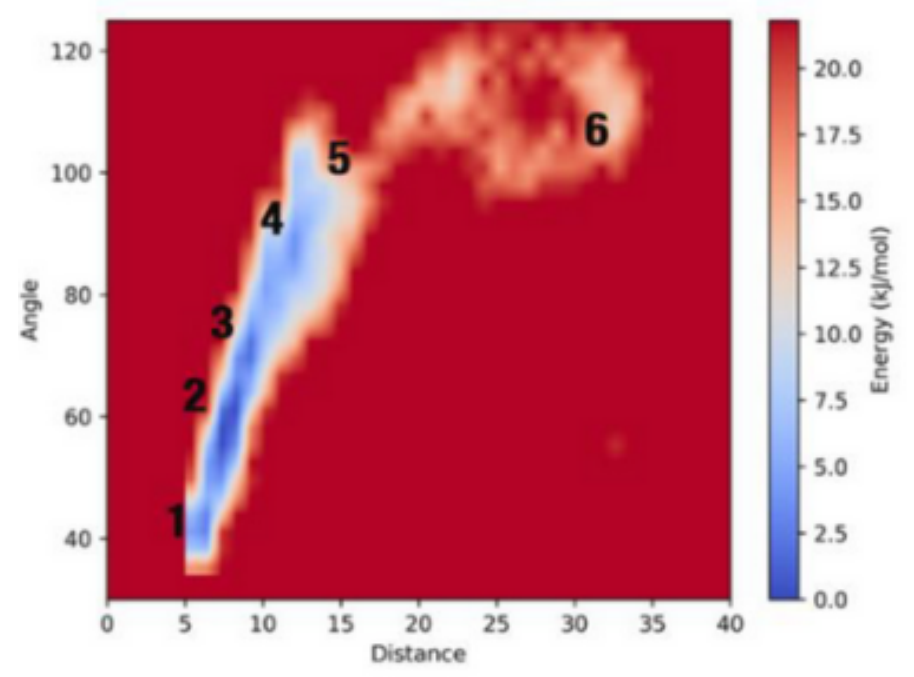

Figura 7. Gráfico de FEL (free energy landscape). Esse gráfico usa a cor para indicar a variação de energia (dada 
em $\mathrm{kJ} / \mathrm{mol}$ ), o eixo $X$ para indicar a distância de mobilidade do ligante em relação à proteína (dada em ângströms) e o eixo Y para indicar a variação de ângulo desse mesmo ligante (veja que o eixo vai de 20 a $\left.120^{\circ}\right)$. Números destacam seis diferentes estados dessa proteína. Fonte: adaptado de [3].

\section{Contatos}

A visualização de contatos é mais utilizada para avaliar interações entre proteína e ligante. O uso mais comum está na análise de estruturas estáticas, como interações entre resíduos de partes de estruturas tridimensionais de proteínas. Entretanto, gráficos de linha do tempo podem ser utilizados para demonstrar a variação de contatos conforme a dinâmica ocorre. A Figura 8 apresenta um gráfico de linha do tempo para uma dinâmica molecular de avaliação do escape do ligante do sítio ativo. Aqui vemos resíduos que interagiram com o ligante no caminho de saída dele, além de uma estimativa visual de quanto tempo ficaram interagindo.

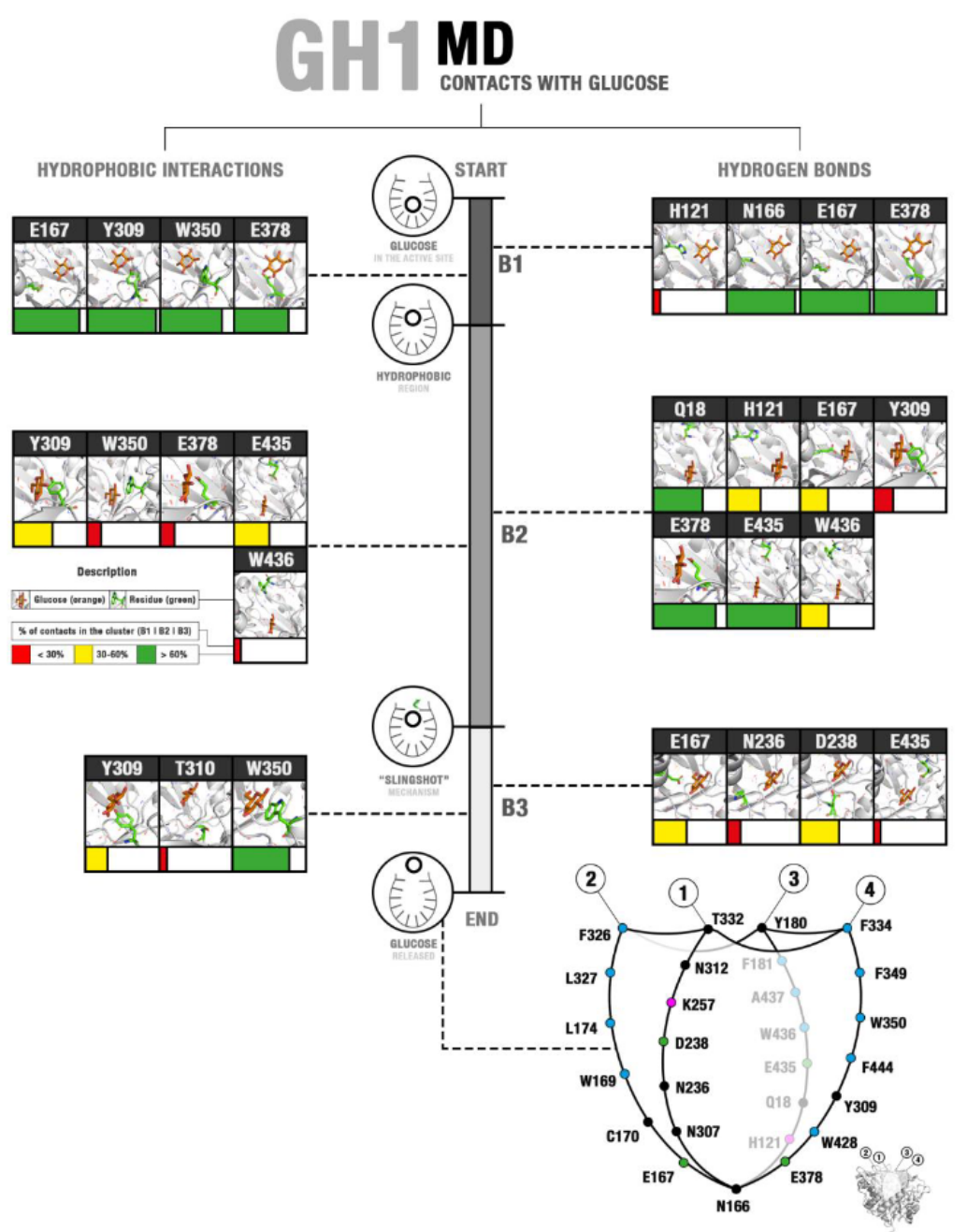

Figura 8. Variação de contatos para uma série de resíduos do bolsão catalítico de uma enzima beta-glicosidase da família GH1 com um ligante (no caso, glicose). O tamanho das barras indica o percentual de tempo em que cada resíduo ficou interagindo com o ligante. 
As barras coloridas em verde indicam resíduos que mais interagiram em determinado período de tempo (o gráfico mostra três períodos distintos: B1, B2 e B3). Barras amarelas indicam um nível médio de interação e vermelha pouca interação. Fonte: adaptado de [3].

\section{Raio de Giro}

Bastante usado para estudo de enovelamento de peptídeos e proteínas. 0 raio de giro está relacionado ao deslocamento do centro de massa da proteína em relação a um eixo. Simplificando, quanto mais volumosa uma proteína, maior o seu raio de giro. Nesse caso, podemos dizer que quando uma proteína está desestruturando, o seu raio de gira aumenta.

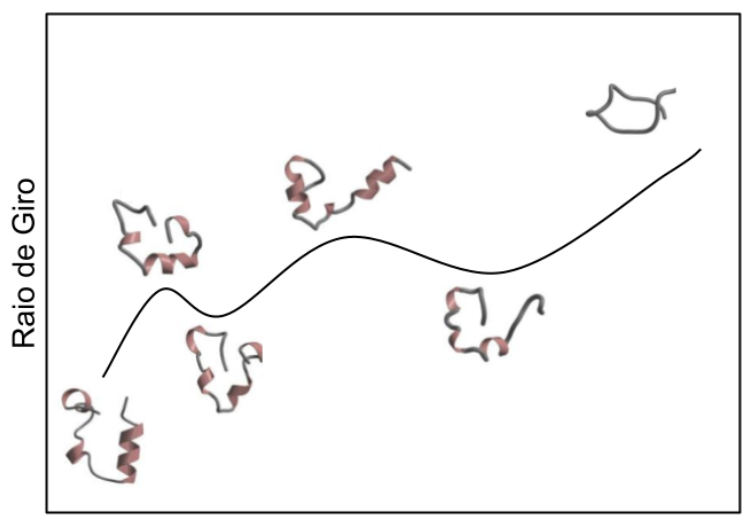

Tempo de Simulação

Figura 9. Exemplo de gráfico ilustrando raio de giro por tempo de simulação. Fonte: próprio autor.

\section{Apenas mostre o filme}

Obviamente em artigos impressos não há como visualizar (sinto muito se você está lendo uma versão impressa deste artigo), mas quando se trata de revistas acessadas em meio digital é possível incluir vídeos interativos. Nesse caso, plataformas de compartilhamento de dados de pesquisa como o Zenodo ou plataformas de compartilhamento de vídeos como o YouTube podem ser úteis. Veja um exemplo a seguir:

Neste vídeo, vemos as interações da molécula de glicose com resíduos de uma proteína beta-glicosidase. Vídeo gerado usando VMD.

\section{Apenas transcrevendo o que foi observado no texto}

Não é o "melhor dos mundos", mas também é uma possibilidade. Nesse caso, seus leitores terão que confiar na sua habilidade de contar o que aconteceu.

\section{Show Your Data}

Outra opção seria disponibilizar os arquivos gerados pela simulação para que qualquer pessoa consiga reproduzi-los em seu próprio computador. Entretanto, deve-se considerar que os arquivos brutos de uma dinâmica 
podem requisitar muito espaço para armazenamento, o que dificulta, por exemplo, o compartilhamento pela internet.

\section{As três dinâmicas}

No geral, podemos dizer que existem três métodos de dinâmica molecular: (i) mecânica molecular ( $\mathrm{MM}$, dinâmica clássica ou mecânica clássica), que se baseia na integração das leis de movimento de Newton; (ii) mecânica quântica (MQ), a partir das equações quânticas, como por exemplo a equação de Schrödinger; e os (iii) métodos híbridos de MM e MQ.

Esses métodos possuem algumas diferenças importantes, impactando por exemplo no tempo de execução. É claro que devemos levar em consideração que tanto a quantidade de tempo necessária para o processamento quanto o tipo de dinâmica que será aplicado estão relacionados com a pergunta a ser respondida. Se a questão avaliada pelo pesquisador tem relação com uma interação proteína-ligante, o tempo pode ser um pouco menor do que se o pesquisador deseja ver somente a estabilidade dela. E não podemos nos esquecer dos métodos de dinâmica acelerada, metadinâmica, umbrellasampling, Monte-Carlo... mas tudo isso é assunto para um outro artigo. Até mais!

\section{Referências}

1. Tousignant A, Pelletier JN. Protein Motions Promote Catalysis. Chemistry \& Biology. 2004;11:1037-42. doi:10.1016/j.chembiol.2004.06.007.

2. Karplus M. Aspects of Protein Reaction Dynamics: Deviations from Simple Behavior. J Phys Chem B. 2000;104:11-27. doi:10.1021/.jp993555t.

3. Costa LSC, Mariano DCB, Rocha REO, Kraml J, Silveira CH da, Liedl KR, et al. Molecular Dynamics Gives New Insights into the Glucose Tolerance and Inhibition Mechanisms on $\beta$-Glucosidases. Molecules. 2019;24:3215. doi:10.3390/molecules24183215.

4. Lima LHF de, Fernandez-Quintéro M, Rocha REO, Mariano DCB, Melo-Minardi RC de, Liedl KR. Conformational flexibility correlates with glucose tolerance for point mutations in $\beta$-glucosidases - A computational study. Journal of Biomolecular Structure and Dynamics. 2020;0 ja:1-20.

doi:10.1080/07391102.2020.1734484. 